\title{
Entrapment of a pulmonary artery catheter inside a knotted percutaneous sheath introducer
}

\author{
Ning Nan Wang, MD • Roupen Hatzakorzian, MD • \\ George Carvalho, MD $\cdot$ Phil Waters, MD
}

Received: 8 February 2015/Accepted: 24 February 2015/Published online: 14 March 2015

(C) Canadian Anesthesiologists' Society 2015

An 82-yr-old male (who consented to this report) was scheduled to undergo aortic valve replacement for aortic stenosis and coronary artery bypass surgery. After induction of general anesthesia, an 8.5 Fr percutaneous sheath introducer (Arrow International, PA, USA) was inserted into the right internal jugular vein under ultrasound guidance. A 7.5 Fr pulmonary artery catheter (PAC) (Biosensors International, Singapore) was then threaded through the sheath to $54 \mathrm{~cm}$ without difficulty and without wedging. A routine postoperative chest $x$-ray showed what appeared to be a semi-loop of the PAC in the right ventricle with the distal tip in the main pulmonary artery. On postoperative day 1 , resistance was encountered on removal of the PAC, and a subsequent chest $x$-ray confirmed a knot at the distal end of the introducer sheath (Figure). As a result, the introducer sheath and PAC were removed via a transverse jugular venotomy under general anesthesia, and the patient was discharged home on postoperative day 5 without further complications.

Many previous reports have described various knotted intravascular devices, including arteriography catheters, central venous infusion catheters, guidewires, pacemaker electrodes, and PACs. ${ }^{1,2}$ Ours is a novel report describing a knotted introducer sheath with a PAC within it. Management of knotted intravascular devices includes percutaneous techniques performed in the interventional radiology suite or surgical intervention. ${ }^{3}$ The initial postoperative chest $x$-ray showing a semi-loop formation in the right ventricle should have triggered removal of the PAC under fluoroscopic guidance using an appropriate guidewire. This may have prevented the subsequent need for surgery.
N. N. Wang, MD · G. Carvalho, MD · P. Waters, MD

Department of Anesthesia, Royal Victoria Hospital, McGill

University Health Centre, Montreal, QC, Canada

R. Hatzakorzian, MD ( $₫)$

Department of Anesthesia and Critical Care, Royal Victoria

Hospital, McGill University Health Centre, Montreal, QC,

Canada

e-mail: roupenhatz@hotmail.com;

roupen.hatzakorzian@muhc.mcgill.ca 
Figure Left: Chest $x$-ray

showing a knot at the distal end of the introducer sheath. Right: Pulmonary artery catheter inside the knotted percutaneous sheath introducer after being surgically removed
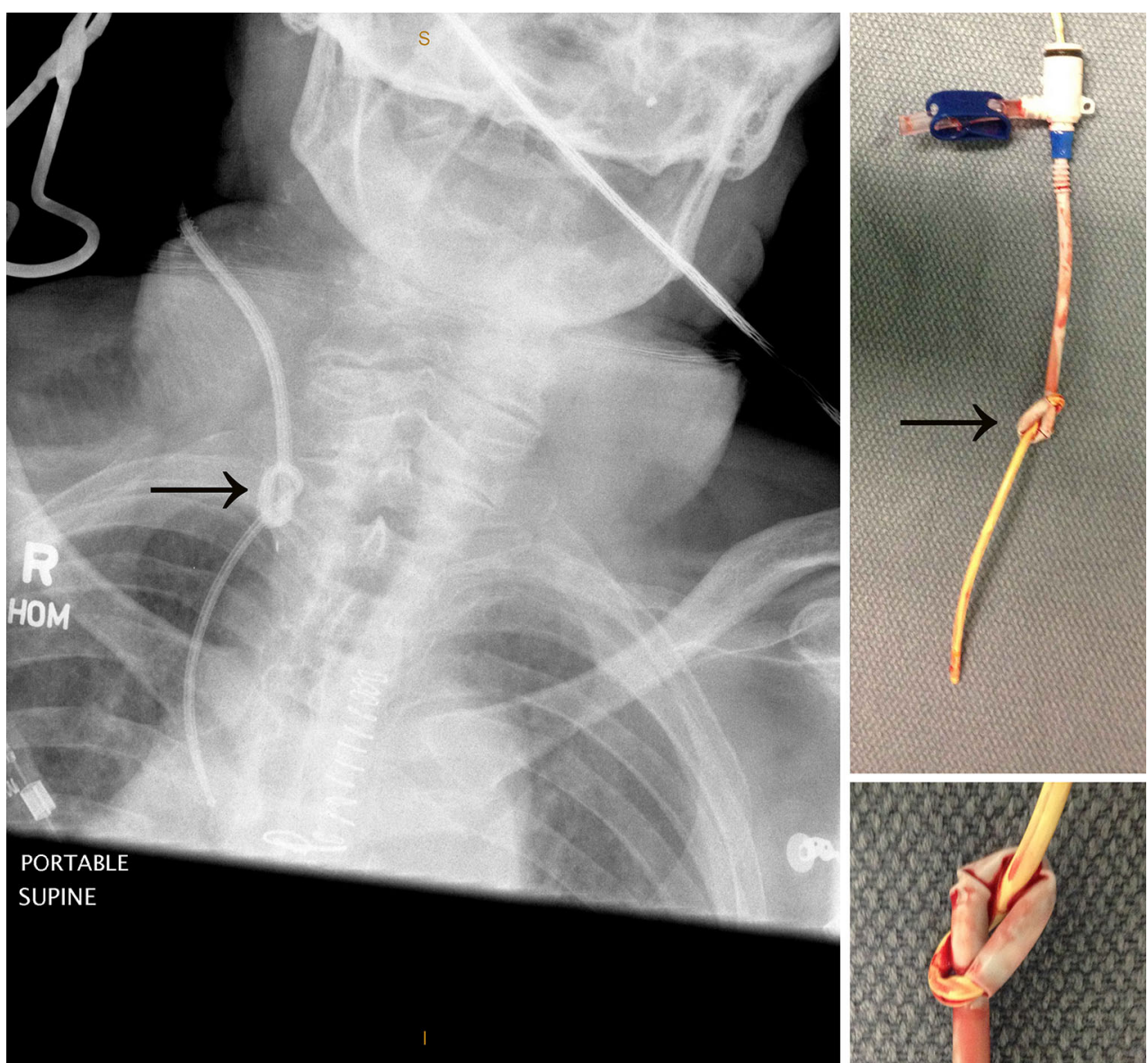

Conflicts of interest None declared.

\section{References}

1. Colbert S, O'Hanlon DM, Quill DS, Keane P. Swan Ganz catheter — all in a knot. Eur J Anaesthesiol 1997; 14: 518-20.
2. Karanikas ID, Polychronidis A, Vrachatis A, Arvanitis DP Simopoulos CE, Lazarides MK. Removal of knotted intravascular devices. Case report and review of the literature. Eur J Vasc Endovasc Surg 2002; 23: 189-94.

3. Katsikis A, Karavolias G, Voudris V. Transfemoral percutaneous removal of a knotted Swan-Ganz catheter. Catheter Cardiovasc Interv 2009; 74: 802-4. 